\title{
Macrophage-stimulating CSF1 is important in liver injury
}

After acute liver injury, hepatic macrophages are important contributors to liver regeneration: they induce cell proliferation and remove necrotic tissue. Macrophage colony stimulating factor (CSF1) is an essential regulator of macrophage development and recruitment, and for this reason plays a vital part in the successfull response to liver damage. Stutchfield et al. now report more-detailed insights into CSF1 effects in liver injury.

"We assessed serum CSF1 levels in humans following either partial

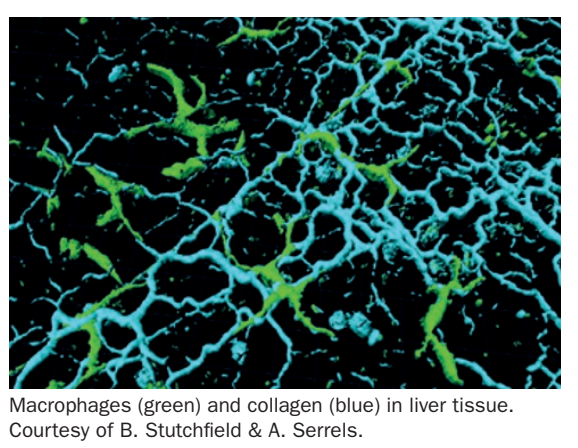

hepatectomy or intoxication with paracetamol. In both these settings, liver tissue is lost acutely in the context of a fairly normal underlying liver, so providing a reasonably controlled environment," explains corresponding author Stuart Forbes. Results confirm a marked effect: in 55 patients who had up to $75 \%$ of their liver tissue removed, CSF1 levels were substantially elevated compared with healthy individuals, and the increase was correlated to the extent of the resection.

In patients with paracetamol-induced acute liver failure, increased serum levels of CSF1 were found in those individuals whose livers regenerated, whereas low serum CSF1 levels were associated with patient deterioration. When the investigators compared the value of CSF1 as a predictor of outcome to the current gold-standard biomarker serum acetyl-HMGB1, CSF1 levels demonstrated better correlations.

As liver biopsies pose a substantial risk for the patient, some experiments were conducted in mice. Subcutaneous administration of CSF1-Fc (a fusion protein designed to prolong the factor's half-life) to mice that had undergone partial hepatectomy was followed by profound macrophage accumulation in the liver (from in situ proliferation, monocytederived infiltration and differentiation), and increased hepatocyte proliferation and liver size 4 days after treatment. Hepatic macrophages displayed enhanced phagocytic capabilities.

Equally, when mice were treated with CSF1-Fc $12 \mathrm{~h}$ after paracetamol intoxication, macrophage populations and liver weight expanded. After these promising results, Forbes will now focus on human work again: "We are keen to see CSF-1 supplementation tested as a potential clinical therapy in the setting of liver failure."

Christine Weber

Original article Stutchfield B. M. et al. CSF1 restores innate immunity following liver injury in mice and serum levels indicate outcomes of patients with acute liver failure. Gastroenterology doi:10.1053/j.gastro.2015.08.053 